\title{
The indications for and timing of haemodialysis in critically ill patients with acute kidney injury in Johannesburg, South Africa
}

\author{
P M Brown, BSc (Hons), MB BCh, DA (SA), FCA (SA), MMed (Anaesthesiol); OrcID 0000-0001-9502-96470; \\ L Redford, MB BCh, DA (SA), FCA (SA), MMed (Anaesthesiol); OrcID 0000-0001-6992-5763; \\ S Omar, MB ChB, FCPath (SA) Chem, DA (SA), Critical Care (SA); OrcID 0000-0001-8494-1518 \\ Department of Anaesthesiology, Faculty of Health Sciences, University of the Witwatersrand, Johannesburg, South Africa
}

Corresponding author: P M Brown (pduncan@tiscali.co.za)

\begin{abstract}
Background. Acute kidney injury (AKI) is common among patients admitted to the intensive care unit (ICU). It is an independent risk factor for morbidity and mortality. The optimal timing of renal replacement therapy (RRT) remains unknown, resulting in a wide variation in observed current practices. There is a paucity of data on current practices within ICUs in South Africa.

Objectives. To describe current practices in the timing of RRT in patients with AKI admitted to the ICU. The secondary objectives were to describe the patient characteristics, severity of illness scores, staging at initiation of RRT, outcome at ICU discharge, and to estimate and describe delays in the initiation of RRT.

Methods. A retrospective, descriptive study was conducted in an adult academic ICU in Soweto from 1 January 2014 to 31 December 2015.

Results. There were $2152 \mathrm{ICU}$ admissions over the 2 years. Less than a tenth of the patients $(3.5 \% ; n=76)$ required RRT and the majority had sepsis (83\%). The most common indication for RRT was oliguria/anuria (50\%; $n=38)$, followed by worsening urea/creatinine (29\%; $n=22)$, metabolic acidosis $(11.8 \% ; n=9)$, refractory hyperkalaemia $(5.3 \% ; n=4)$, fluid overload $(2.6 \% ; n=2)$ and other $(1.3 \% ; n=1)$. More than half of the patients $(55 \% ; n=42)$ had RRT instituted on admission day $\left(\mathrm{D}_{0}\right)$, while $45 \%(n=34)$ had RRT initiated after $\mathrm{D}_{0}\left(\mathrm{D}_{1-21}\right)$. RRT was initiated at stage 3 AKI in $90 \%$ and $94 \%$ of $\mathrm{D}_{0}$ RRT group and $\mathrm{D}_{1-21}$ RRT group, respectively. The median (interquartile range (IQR)) time to starting RRT was 4 (4) hours once the decision to initiate RRT was made. The composite outcome of death, RRT dependence and diuretic dependence at ICU discharge was $21 \%$ and there was no difference between the two groups $(p=0.22)$. The ICU mortality was $3 \%$.

Conclusion. The sampled population was young, predominantly male and had post emergency surgery with a high burden of sepsis and HIV. The observed current threshold for RRT was late (stage 3 AKI with classic/emergent indications) with outcomes comparable with the reviewed literature.
\end{abstract}

Keywords. AKI; timing; renal replacement therapy.

South Afr J Crit Care 2021:37(1):51-55. https://doi.org/10.7196/SAJCC.2021.v37i2.458

Contributions of the study. The present study adds insight into the practice of initiating RRT in patients admitted to the ICU with AKI. These data have previously not been described in the South African context. The patient population differed from the literature in that they were young, predominantly male and had post-emergency surgery with a high burden of sepsis and HIV.

Acute kidney injury (AKI) represents a broad spectrum of pathological processes ranging from clinically undetectable changes to severe injury, which is associated with either reversible or permanent and complete loss of renal function. ${ }^{[1]}$ There is evidence suggesting that even mild reversible AKI confers significant independent risk for morbidity and mortality, ${ }^{[2-7]}$ and contributes to increased healthcare costs. ${ }^{[8]}$ There is a scarcity of data to quantify the incidence of AKI in intensive care units (ICUs) in South Africa (SA); however, it is likely to be higher than that of the developed countries as a result of the burden of disease associated with AKI in this region. ${ }^{[3]}$

It was postulated that initiating dialysis prior to the development of classic indications may be beneficial due to high morbidity and mortality associated with AKI. The risks associated with renal replacement therapy (RRT) need to be balanced against the possible benefits of early RRT, especially considering that some patients with AKI may have spontaneous recovery of renal function. ${ }^{[9]}$ Early initiation of RRT prior to the onset of severe AKI could potentially prevent kidney-specific damage and remote organ injury resulting from fluid overload, systemic inflammation, electrolyte and metabolic imbalance, while promoting greater kidney recovery. ${ }^{[10,11]}$ Three large prospective randomised control trials (RCTs) have been conducted to assess the value of early RRT. The results from the artificial kidney initiation in kidney injury (AKIKI) trial $^{[12]}$ and the initiation of dialysis early v. delayed in the intensive care unit (IDEAL-ICU) trial ${ }^{[13]}$ showed that there is no mortality benefit 
in early initiation of RRT ( $p=0.79$ and $p=0.38$, respectively), whereas the effect of early v. delayed initiation of renal replacement therapy on mortality in critically ill patients with acute kidney injury (ELAIN) trial ${ }^{[14]}$ found that the mortality rate was reduced (39.3\% v. $53.7 \%)$ in the group that initiated RRT early compared with the late group (hazard ratio (HR) 0.66 ; $95 \%$ confidence interval (CI) 0.45 - 0.97). A recent meta-analysis which included seven RCTs concluded that there was no difference in mortality between early and late initiation of RRT $(p=0.97) \cdot{ }^{[15]}$

Current recommendations for initiation of RRT in the setting of AKI are not graded due to a lack of high-quality evidence. ${ }^{[2]}$ This has resulted in a wide variation in interpretation and implementation of RRT among clinicians. ${ }^{[16]}$ There is a paucity of local data in the literature, thus we undertook to describe local practices in managing RRT in AKI in a developing country.

\section{Methods \\ Design and setting}

A retrospective chart review was performed at the Chris Hani Baragwanath Academic Hospital main ICU, which is a combined adult and paediatric multidisciplinary ICU. Ethical approval was obtained from the Human Research Ethics Committee at the University of the Witwatersrand (ref. no. M170684). The study period extended from 1 January 2014 to 31 December 2015. There is no protocol in place for the initiation of RRT; therefore, clinicians use their discretion.

\section{Patients and data}

All adult patients with AKI who underwent RRT were eligible for inclusion, while those with known chronic kidney disease and prior nephrectomy were excluded. Data were collected on the day of admission as well as on the day of RRT if they differed. Data points pertaining to demographics, metabolic, renal, ventilation, oxygenation, haemodynamic, septic and haematological markers as well as patient outcome were entered into a Microsoft Excel spreadsheet. In addition, the simplified acute physiology score (SAPS) II and the sequential organ failure assessment (SOFA) scores were calculated. This was performed by the principal investigator (PMB).

\section{Statistical analysis}

All data were assessed for normality. All independent medians were compared with the Mann-Whitney $U$-test, while dependent medians were compared with the Wilcoxon matched paired test. Categorical data were assessed with the $\chi^{2}$ test. Data analysis was carried out using Statistica, version 13.3 (TIBCO Software Inc., USA). A $p$-value $<0.05$ was considered to be significant.

Calculation of sample size was based on an estimated incidence of RRT of $5-10 \%, 95 \%$ confidence and a precision of $5 \%$. The minimum required sample size was 73 patients. We recruited participants over a 2-year period (1 January 2014 until 31 December 2015) to ensure this minimum sample size was achieved.

\section{Results}

There were $2171 \mathrm{ICU}$ admissions during the 2-year study period. The majority of these admissions ( $n=1315)$ did not meet the criteria for the diagnosis of AKI (Fig. 1). The overall incidence of AKI was 39.4\% ( $n=856 / 2$ 171). Of the 856 patients who met the inclusion criteria, 76 patients were dialysed and represent the study population.

The median (interquartile range (IQR)) age of the study participants was $35.5(25-46)$ years. The majority of them were male $(52.6 \%)$. The

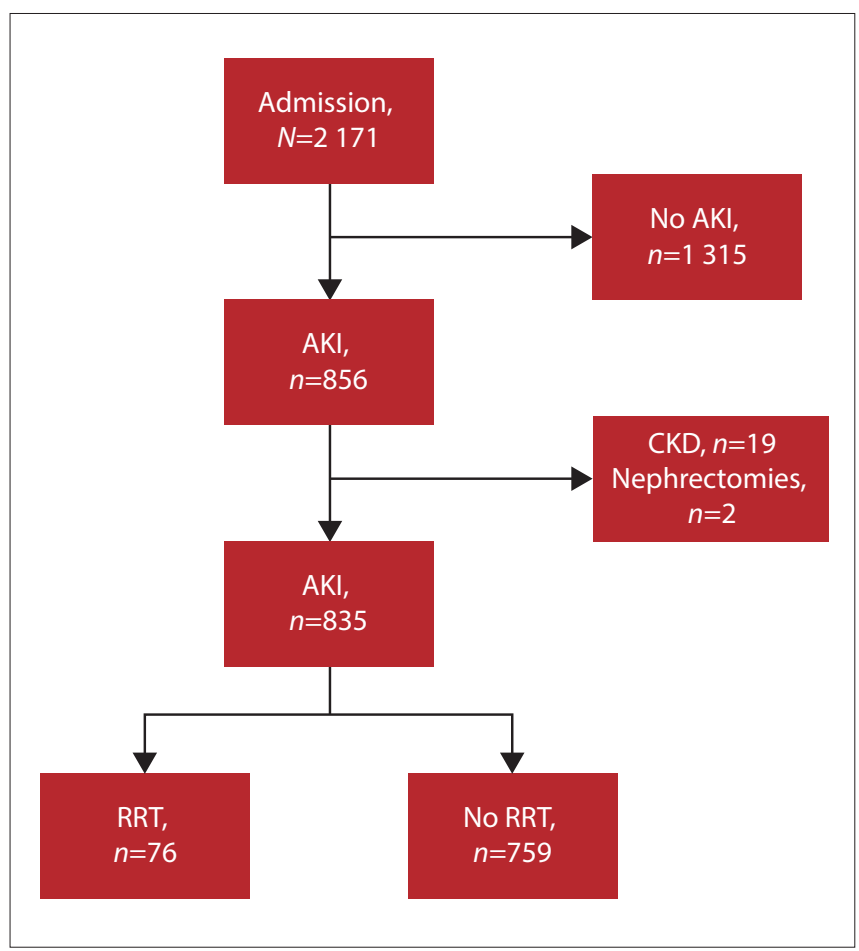

Fig. 1. Flow diagram showing patient realisation. (AKI = acute kidney injury; $C K D=$ chronic kidney disease; $R R T=$ renal replacement therapy).

median SAPS II score (43) gave a predicted mortality rate of 30.6\%. The baseline characteristics are shown in Table 1.

The relative frequencies for the indications for RRT were oliguria/ anuria $(50 \% ; n=38)$, worsening urea/creatinine $(29 \% ; n=22)$, acidosis (11.8\%; $n=9)$, refractory hyperkalaemia $(5.3 \% ; n=4)$, fluid overload (2.6\%; $n=2)$, and no absolute indication $(1.3 \% ; n=1)$.

The majority of patients $(55 \% ; n=42)$ had RRT instituted on admission day $\left(\mathrm{D}_{0} \mathrm{RRT}\right)$, while $45 \%(n=34)$ were initiated between day 1 and 21 $\left(D_{1-21} R R T\right)$. Table 2 summarises the relative frequencies of the KDIGO stage for AKI between the two groups on admission day and the day of initiation of RRT.

Patients admitted in KDIGO stage 1 and 2 were significantly less likely to undergo RRT on admission day (odds ratio (OR) 0.21; CI 0.06 0.73). Overall, the KDIGO stage increased significantly from $\mathrm{D}_{0}$ to RRT day for the $\mathrm{D}_{1-21}$ RRT group ( $\left.p=0.0004\right)$. Comparisons between the two RRT groups $\left(\mathrm{D}_{0}\right.$ RRT v. $\left.\mathrm{D}_{1-21} \mathrm{RRT}\right)$ are shown in Table 1.

The cumulative number of the surgical sub-specialities (general surgery ( $n=15)$, obstetrics and gynaecology $(n=13)$, trauma $(n=17)$ and orthopaedics $(n=3))$ makes post-surgical patients $(63 \% ; n=48)$ the largest group requiring RRT, followed by medical patients $(37 \% ; n=28)$. Almost all patients $(n=35 / 36)$ who underwent surgery prior to ICU admission had emergency surgery.

The majority of the study participants $(61.8 \% ; n=47)$ had no known comorbidities. A tenth of the participants had HIV (13.2\%; $n=10)$, followed by hypertension $(10.5 \% ; n=8)$, and diabetes $(6.6 \% ; n=5)$. Multiple comorbidities affected $7.9 \%$ of the study participants $(n=6)$.

There was no difference in median (IQR) SOFA score $10(8-12)$ on the day of RRT between the two groups $(p=0.67)$. However, in the group undergoing RRT after $\mathrm{D}_{0}$, the SOFA score increased from a median (IQR) of 7 (4.5 - 9.5) on admission to 10 ( 8 - 12) on the RRT day ( $p=0.0004)$. Once a decision to initiate RRT was made, the median (IQR) time to 
Table 1. Summary of study results

\begin{tabular}{|c|c|c|c|c|}
\hline & $\begin{array}{l}\text { All at } \mathrm{D}_{0} \\
\text { median }(\mathrm{IQR})^{*}\end{array}$ & $\begin{array}{l}\mathrm{D}_{0} \mathrm{RRT} \\
\text { median }(\mathrm{IQR})^{*}\end{array}$ & $\begin{array}{l}\mathrm{D}_{1-21} \mathrm{RRT}, \\
\text { median }(\mathrm{IQR})^{*}\end{array}$ & $p$-value \\
\hline \multicolumn{5}{|l|}{ Demographics } \\
\hline Sex (male), $n(\%)$ & $40(52.6)$ & $23(54.8)$ & $17(50)$ & 0.68 \\
\hline Age (years) & $35.5(21)$ & $34.5(18)$ & $39.5(24)$ & 0.39 \\
\hline SOFA score & $9(4.5)$ & 10 & 10 & 0.67 \\
\hline Predicted mortality SAPS score & $43(21)$ & $45.5(22)$ & $41.5(17)$ & 0.04 \\
\hline \multicolumn{5}{|l|}{ Blood gas } \\
\hline $\mathrm{pH}$ & $7.28(0.21)$ & $7.273(0.238)$ & $7.278(0.167)$ & 0.56 \\
\hline $\mathrm{BE}(\mathrm{mmol} / \mathrm{L})$ & $-10.8(9)$ & $-12.1(7.9)$ & $-7.2(7.2)$ & 0.35 \\
\hline Lactate $(\mathrm{mmol} / \mathrm{L})$ & $3.1(4.4)$ & $2.550(4)$ & $3.25(4.4)$ & 0.42 \\
\hline $\mathrm{K}^{+}(\mathrm{mmol} / \mathrm{L})$ & $4.7(1.4)$ & $4.95(2.1)$ & $4.4(1.1)$ & 0.05 \\
\hline $\mathrm{Na}_{2}(\mathrm{mmol} / \mathrm{L})$ & $137(9.5)$ & $135.5(10)$ & $138(9)$ & 0.01 \\
\hline $\mathrm{PaCO}_{2}(\mathrm{mmHg})$ & $32(13.1)$ & $31(13.1)$ & $34(10.5)$ & 0.1 \\
\hline $\mathrm{P} / \mathrm{F}$ ratio & $264(183)$ & $264.167(193.095)$ & $262.5(184)$ & 0.69 \\
\hline \multicolumn{5}{|l|}{ Biochemistry } \\
\hline $\mathrm{S}_{\mathrm{Cr}}(\mathrm{mmol} / \mathrm{L})$ & $349(438)$ & $505(459)$ & $331(203)$ & 0.00 \\
\hline Albumin (g/L) & $24(8.5)$ & $24(9)$ & $25(8.5)$ & 0.47 \\
\hline Phosphate (mmol/L) & $1.61(1.29)$ & $1.97(1.66)$ & $1.37(0.950)$ & 0.08 \\
\hline Bilirubin (mmol/L) & $13.5(20)$ & $14.5(20)$ & $11.5(21.5)$ & 0.62 \\
\hline $\mathrm{Ca}^{2+}(\mathrm{mmol} / \mathrm{L})$ & $2.08(0.34)$ & $2.070(0.320)$ & $2.2(0.350)$ & 0.88 \\
\hline Cumulative fluid balance $(\mathrm{mL})$ & $2311(1721)$ & 0 & $2303(1730)$ & 0.00 \\
\hline \multicolumn{5}{|l|}{ Cardiovascular } \\
\hline MAP (mmHg) & $71(29)$ & $69.33(29.66)$ & $80(29.33)$ & 0.11 \\
\hline Heart rate $(/ \mathrm{min})$ & $123(34)$ & $123.5(41)$ & $121(27)$ & 0.64 \\
\hline \multicolumn{5}{|l|}{ Ventilation } \\
\hline Peak ventilator pressure (mmHg) & $20(13)$ & $20(5)$ & $20(5)$ & 0.74 \\
\hline Invasive ventilation, $n$ (\%) & $53(69.7)$ & $27(64.2)$ & $26(67.6)$ & 0.7 \\
\hline Respiratory rate (breaths/min) & $26(13)$ & $27(14)$ & $24(10)$ & 0.5 \\
\hline \multicolumn{5}{|l|}{ Haematology and infection } \\
\hline White cell count $\left(\times 10^{9} / \mathrm{L}\right)$ & $12.1(9.7)$ & $15.44(10.8)$ & $9.3(6.070)$ & 0.001 \\
\hline $\mathrm{C}$-reactive protein $(\mathrm{mg} / \mathrm{L})$ & $195(159)$ & $198(138)$ & $181(215.5)$ & 0.32 \\
\hline Procalcitonin $(\mu \mathrm{g} / \mathrm{L})$ & $38(76)$ & $36.9(81.63)$ & $214.5(165)$ & 0.43 \\
\hline Sepsis present, $n(\%)$ & $56(73.7)$ & $33(78.6)$ & $23(67.6)$ & 0.38 \\
\hline $\mathrm{Hb}(\mathrm{g} / \mathrm{dL})$ & $9.2(3.4)$ & $8.9(3.1)$ & $9.65(4.2)$ & 0.05 \\
\hline Platelet $\left(\times 10^{9} / \mathrm{L}\right)$ & $168(185)$ & $128(143)$ & $214.5(165)$ & 0.04 \\
\hline INR & $1.31(0.34)$ & $1.29(0.37)$ & $1.49(0.6)$ & 0.04 \\
\hline aPTT (sec) & $40(17.5)$ & $40(15.8)$ & $48.25(31.9$ & 0.36 \\
\hline \multicolumn{5}{|l|}{ Outcomes } \\
\hline In-ICU mortality, $n(\%)$ & $2(2.6)$ & $1(2.4)$ & $1(2.9)$ & 0.88 \\
\hline Composite (death, RRT/diuretic dependence), $n$ (\%) & $21(27.6)$ & $14(33.3)$ & $7(20.6)$ & 0.22 \\
\hline
\end{tabular}

Table 2. AKI staging of the two patient groups

\begin{tabular}{|c|c|c|c|c|}
\hline \multirow[b]{2}{*}{ KDIGO Stage } & \multicolumn{2}{|c|}{ Staging on admission } & \multicolumn{2}{|c|}{ Staging on RRT day } \\
\hline & $\mathrm{D}_{0}$ RRT $n(\%)$ & $\mathrm{D}_{1-21}$ RRT $n(\%)$ & $\mathrm{D}_{0}$ RRT $n(\%)^{*}$ & $\mathrm{D}_{1-21} \mathrm{RRT} n(\%)$ \\
\hline No AKI & 0 & $7(20.6)$ & - & 0 \\
\hline Stage 1 & 0 & $5(14.7)$ & - & 0 \\
\hline Stage 2 & $4(10)$ & $4(11.8)$ & - & $2(6)$ \\
\hline Stage 3 & $38(90)$ & $18(53)$ & - & $32(94)$ \\
\hline
\end{tabular}


starting RRT was $4(2-6)$ hours. There was no significant difference between the $\mathrm{D}_{0}$ RRT group and the $\mathrm{D}_{1-21}$ RRT group $(p=0.34)$.

The composite of death, RRT dependence and diuretic dependence at ICU discharge was $21 \%(n=16 / 76)$. There was no significant difference in the composite outcome between the two groups $(p=0.22)$. The overall in ICU mortality was $3 \%(n=2 / 76)$.

\section{Discussion}

The incidence of AKI was $39.4 \%$ in this present study. Internationally, the incidence of AKI in ICU patients ranges from $20-50 \% \cdot{ }^{[1]}$ Our study included admissions to a single unit consisting of both ICU and high-dependency beds. The inclusion of the high care group with a lower severity of illness may have resulted in a lower than expected AKI incidence. This may be compounded by a higher admission and turnover rate in the high dependency unit compared with the ICU. The same factors may also explain the RRT incidence of $4.5 \%$, which appears lower than the incidence of RRT internationally (5 - 10\%). ${ }^{[17]}$

Our study population was unique when compared with others in the literature. The median age of the study population was 35.5 years. The majority of the patients were surgical (63\%) with more than a third of these being trauma patients. Additionally, all but one of the patients who underwent surgery prior to ICU admission were emergency surgical cases. There was a high burden of HIV (13.2\%) in the study population. This is in line with the reported HIV prevalence of $13.5 \%$ in SA. ${ }^{[18]}$ There was also a high frequency of sepsis (83\%) in the population sampled. This is in contrast to the study populations in the AKIKI, IDEAL-ICU and ELAIN trials, where the median age of all groups was $>60$ years, the incidence of reported emergency surgery was $\sim 12 \%$ and HIV was not a significant comorbidity. ${ }^{[12-14]}$

Overall, $90 \%$ or more of our study participants underwent RRT after reaching KDIGO stage 3. Although earlier studies, mostly non-randomised, suggested that early initiation of RRT prior to the development of the classic indications for RRT may confer improved outcomes, ${ }^{[2-5-7,19,20]}$ the most recent evidence of over 2000 patients from randomised trials shows no benefit of this early RRT strategy. ${ }^{[15]} \mathrm{A}$ significant proportion of AKI patients in both the AKIKI and IDEALICU studies spontaneously recovered when RRT was withheld, provided that no classic/emergent indications for RRT arose. ${ }^{[12,14]}$ The practice observed in our study was in keeping with these more recent findings with initiation of RRT in stage 3 AKI (late) using predominantly classic/ emergent indications.

The observed median serum creatinine difference between the $\mathrm{D}_{0}$ RRT and $\mathrm{D}_{1-21}$ RRT groups can be explained by delayed admission to the ICU. This is not unexpected in a resource-limited setting. However, once patients were in ICU, access to RRT was better.

The AKIKI trial population had a higher severity of illness score at admission in comparison with ours; however, the SOFA score at initiation of RRT was similar, indicating a common threshold to initiate RRT. The discrepancy between severity of illness and organ dysfunction may be explained by the fact that our group had similar organ dysfunction necessitating support, but a greater underlying reversibility when compared with the AKIKI trial.

Despite a relatively high composite outcome, the early mortality was only $3 \%$ at ICU discharge. Several factors may explain this finding. The first is that in a resource-limited setting, patients admitted to the ICU are strictly triaged to make sure that resources are distributed equitably. This may result in a selection bias where patients with likely better outcomes are admitted. Secondly, it is likely that a similar selection bias for RRT within the ICU exists for the same resource constraints. Finally, outcomes at ICU discharge are generally lower than at hospital discharge and at 90 days. Unfortunately, we did not look at all the patients with AKI to assess if any patients who required RRT did not receive it. Decisions not to escalate therapy including RRT were also not examined and it is possible that patients with a better prognosis may have been selected.

Classic indications were the predominant trigger for RRT initiation in this present study. This is in keeping with the delayed groups of the IDEAL ICU and AKIKI trials. ${ }^{[12,14]}$ The IDEAL-ICU delayed group had RRT initiated for comparable indications as our study population. These were metabolic acidosis ( $8 \%$ v. $11 \%)$, hyperkalaemia ( $4 \%$ v. $5.3 \%)$, fluid overload (2.6\% v. $2.6 \%)$ and other ( $2 \%$ v. $1.3 \%)$.

Patients in this present study received RRT predominantly when they had reached stage 3 AKI $\left(90 \%\right.$ and $94 \%$ for the $D_{0}$ RRT and $D_{1-21}$ RRT groups, respectively). Of the group who received dialysis thereafter ( $D_{1-21}$ RRT group), $47 \%$ were classified with stage 1 or stage 2 AKI on admission. This group is of great interest. The ability to predict deterioration before it happens may provide a therapeutic or preventive window.

\section{Study limitations}

This was a retrospective study with a small sample size that employed convenience sampling over a period of 2 years at a single centre. The aforementioned can all lead to a non-representative sample of the general population. The study extracted information from patient charts, clinical notes as well as a database that is populated for each patient. This was done solely by the PMB with knowledge of the data capturing system in place. This decreased the occurrence of incorrect information and missing data points. The patients with AKI who were not dialysed were not assessed further. This group of patients may represent a subset of patients that needed dialysis but were not afforded it because of limited resources, they are haemodynamically unstable or have poor prognosis. The study period (2014 - 2015) may represent a dated study period; however, the absolute and relative indications for RRT remain unchanged.

\section{Conclusion}

The study population was young, predominantly male and had postemergency surgery with a high burden of sepsis and HIV. The observed current threshold for RRT was late (stage 3 AKI with classic/emergent indications) with outcomes comparable with reviewed literature. Further research looking at patients that were not dialysed but potentially required it would offer greater insights. Expanding the study population to include other centres and performing a prospective study should also be considered.

Declaration. This study was done in partial fulfilment of an MMed degree in anaesthesia.

Acknowledgements. None.

Author contributions. PMB performed all the data collection and wrote the draft of the manuscript. SO and LR supervised the student and revised the manuscript. All the authors approved the final manuscript for publication Funding. None.

Conflicts of interest. None.

. Case J, Khan S, Khalid R, Khan A. Epidemiology of acute kidney injury in the intensive care unit. Crit Care Res Pract 2013;2013:1-9. https://doi.org/10.1155/2013/479730

2. Section 2: AKI Definition. Kidney Int Suppl 2012;2(1):19-36. https://doi.org/10.1038/ kisup.2011.32 
3. Naicker S, Aboud O, Gharbi MB. Epidemiology of acute kidney injury in Africa. Semin Nephrol 2008;28(4):348-353. https://doi.org/10.1016/j.semnephrol.2008.04.003

4. Skinner DL, Hardcastle TC, Rodseth RN, Muckart DJJ. The incidence and outcomes of acute kidney injury among patients admitted to a level I trauma unit. Injury 2014;45(1):259-264. https://doi. org/10.1016/j.injury.2013.07.013

5. Pannu N, Gibney RN. Renal replacement therapy in the intensive care unit. Ther Clin Risk Manag 2005;1(2):141-150. https://doi.org/10.2147\%2Ftcrm.1.2.141.62908

6. Mehta RL, Kellum JA, Shah SV, et al. Acute Kidney Injury Network: Report of an initiative to improve outcomes in acute kidney injury. Crit Care 2007;11(2):R31. https://doi.org/10.1186\%2Fcc5713

7. Cruz DN, Ricci Z, Ronco C. Clinical review: RIFLE and AKIN - time for reappraisal. Crit Care 2009;13(3):211. https://doi.org/10.1186/cc7759

8. Pannu N, James M, Hemmelgarn B, Klarenbach S, for the Alberta Kidney Disease Network. Association between AKI, recovery of renal function, and long-term outcomes after hospit discharge. Clin J Am

9. Macedo E, Malhotra R, Bouchard J, Wynn SK, Mehta RL. Oliguria is an early predictor of
higher mortality in critically ill patients. Kidney Int 2011;80(7):760-767. https://doi.org/10.1038/ kigher mortality

10. Shiao C-C, Huang T-M, Spapen HD, Honore PM, Wu V-C. Optimal timing of renal replacement therapy initiation in acute kidney injury: The elephant felt by the blindmen? Crit Care 2017;21(1). https://doi.org/10.1186/s13054-017-1713-2

11. Karvellas CJ, Farhat MR, Sajjad I, et al. A comparison of early v. late initiation of renal replacement therapy in critically ill patients with acute kidney injury: A systematic review and meta-analysis. Crit Care Lond Engl 2011;15(1):R72. https://doi.org/10.1186/cc10061

12. Gaudry S, Hajage D, Schortgen F, et al. Initiation strategies for renal-replacement therapy in the intensive care unit. N Engl J Med 2016;375(2):122-133. https://doi.org/10.1056/NEJMoa1603017
13. Zarbock A, Kellum JA, Schmidt C, et al. Effect of early v. delayed initiation of renal replacement therapy on mortality in critically ill patients with acute kidney injury: The ELAIN randomised clinical trial. JAMA 2016;315(20):2190-2199. https://doi.org/10.1001/jama.2016.5828

14. Barbar SD, Clere-Jehl R, Bourredjem A, et al. Timing of renal-replacement therapy in patients with acute kidney injury and sepsis. N Engl J Med 2018;379(15):1431-1442. https://doi. org/10.1056/nejmoa1803213

15. Pasin L, Boraso S, Tiberio I. Early initiation of renal replacement therapy in critically ill patients: A meta-analysis of randomised clinical trials. BMC Anesthesiol 2019;19(1):62. https://doi org/10.1186/s12871-019-0733-7

16. Joannidis M, Forni LG. Clinical review: Timing of renal replacement therapy. Crit Care Lond Eng 2011;15(3):223. https://doi.org/10.1186/cc10109

17. Tandukar S, Palevsky PM. Continuous renal replacement rherapy. Chest 2019;155(3):626-638 https://doi.org/10.1016\%2Fj.chest.2018.09.004

18. Statistics South Africa. Mid-year population estimates. Pretoria: StatsSA, 2019. http://www.statssa. gov/publications/P0302.pdf

19. Bagshaw SM, George C, Bellomo R, for the ANZICS Database Management Committee. A comparison of the RIFLE and AKIN criteria for acute kidney injury in critically ill patients. Nephrol Dial Transplant 2008;23(5):1569-1574. https://doi.org/10.1093/ndt/gfn009

20. Kellum JA, Prowle JR. Paradigms of acute kidney injury in the intensive care setting. Nat Rev Nephrol 2018;14(4):217-230. https://doi.org/10.1038/nrneph.2017.184

Accepted 25 February 2021. 